\title{
SUSTENTABILIDADE EM SISTEMAS AGRÍCOLAS \\ INTEGRADOS: UMA APLICAÇÃO DO MÉTODO MESMIS EM \\ COOPERATIVA DE PEQUENOS PRODUTORES RURAIS
}

SUSTAINABILITY IN INTEGRATED AGRICULTURAL SYSTEMS:

APPLICATION OF THE METHOD MESMIS IN COOPERATIVE OF SMALL FARMERS

\section{Maria de Fátima Martins}

Doutora em Recursos Naturais da Universidade Federal de Campina Grande (UFCG). Professora do curso de Administração e do Programa de Pós-Graduação em Recursos Naturais da UFCG - Campina Grande (PB) - Brasil.

\section{Gesinaldo Ataíde Cândido}

Doutor em Engenharia de Produção pela Universidade Federal de Santa Catarina (UFSC). Professor do curso de Administração e do Programa de Pós-Graduação em Recursos Naturais da UFCG - Campina Grande (PB) - Brasil.

\section{Alcimara Batista Aires}

Graduada em Administração pela UFCG - Campina Grande (PB) - Brasil.

\section{Endereço para correspondência:}

Maria de Fátima Martins Rua Maria Aparecida Carneiro, 280Catolé - 58410-367-Campina Grande (PB) - Brasil - E-mail: fatimamartins2005@gmail.com

Recebido: 03/10/2015

Aceito: 07/02/2017

\section{RESUMO}

O objetivo deste artigo é analisar a sustentabilidade de sistemas agrícolas com atividades integradas (hidroponia, dessalinização, microalga e aquaponia), tendo como objeto de estudo as atividades da Cooperativa Hidroçu, em São João do Cariri (PB), a partir do Método MESMIS. A pesquisa é caracterizada como descritiva, exploratória e de abordagem quali-quantitativa. Para coleta de dados, utilizou-se de pesquisa documental e de campo. Para análise das informações, triangulação dos dados primários e secundários, embasamento teórico e percepção dos pesquisadores foram empregados. Os resultados evidenciam que as atividades agrícolas da Cooperativa apresentam média contribuição à sustentabilidade no tocante às dimensões econômica e social, e alta contribuição em relação ao aspecto ambiental, por meio de processos integrados, nos quais a hidroponia permite redução dos impactos da atividade agrícola no solo e na preservação dos recursos naturais. Assim, a Cooperativa é vista pelos cooperados como alternativa promissora que gera emprego e renda em uma região caracterizada por longos períodos de estiagem, que inviabilizam a atividade agrícola convencional.

Palavras-chave: agroecossistemas; hidroponia; cooperativismo; indicadores; semiárido; método MESMIS.

\section{ABSTRACT}

The aim of this paper is to assess the sustainability in farming systems with integrated activities (hydroponics, desalination, microalga and aquaponics), with the activities of Hidroçu Cooperative, in São João do Cariri (state of Paraíba, Brazil) as the object of study. The application of the MESMIS Method was employed in such assessment. This research is characterized as descriptive, exploratory, with a qualitative and quantitative approach. For data collection, desk and field research were used. For analysis of the information gathered, triangulation of primary and secondary data, theoretical background and the perception of researchers were employed. The results showed that the agricultural activities of the Cooperative have average contribution to sustainability with regard to economic and social dimensions, and high environmental contribution through integrated processes, in which hydroponics allows the reduction of the impacts of agriculture on soil and preservation of natural resources. Thus, the Cooperative is seen by its associates as a promising alternative that generates jobs and income in a region characterized by long periods of droughts that prevent conventional agriculture.

Keywords: agroecosystems; hydroponic; cooperativism; indicators; semiarid; MESMIS method. 


\section{INTRODUÇÃO}

Os processos de desenvolvimento pelos quais a sociedade moderna já passou ao longo de sua evolução tiveram implicações, tais como: a degradação da base de recursos naturais, o aumento da poluição ambiental, a elevação nos níveis de desigualdade social e de concentração de riqueza, entre outros problemas. Como resposta a essas questões, o conceito de desenvolvimento sustentável surge com a proposta de incorporar outras dimensões às questões econômicas, para resultar em um modelo de desenvolvimento futuro equitativo em distribuição e exploração dos recursos naturais.

Diante dessas questões, as atividades econômicas tiveram de se adaptar para atender às exigências desse novo modelo de desenvolvimento, em que estratégias, processos, atitudes, ações, entres outros aspectos precisaram ser modificados para gerar produtos e serviços que atendessem a essa nova realidade. No contexto das atividades agrícolas, verifica-se uma nova postura dos produtores no sentido de produzir com o menor impacto negativo possível na sociedade e no meio ambiente, buscando gerar rendimentos econômicos, meIhoria da qualidade de vida e preservação das condições ambientais locais.

Marques e Oliveira (2016) chamam a atenção para a emergência de uma agricultura alternativa com a possibilidade de introdução de novas práticas, discussões, performances, instituições para um reposicionamento dos modos locais de organização em torno de uma agricultura ecológica, baseada em práticas locais de produção que se apresentam na contramão da modernização, caracterizadas principalmente pela ausência de agrotóxicos. Esse tipo de produção se refere a um conjunto de práticas produtivas e processos sociais que resultam na incorporação de valores socioambientais na produção agrícola. Constitui um sistema orgânico de produção agropecuária com técnicas específicas e otimização do uso dos recursos naturais e socioeconômicos, normatizados pela Lei $\mathrm{n}^{\circ} 10.831 / 2003$.

Destacam-se alguns fatores de fundamental importância para a construção de uma nova percepção e das discussões atuais em torno do desenvolvimento rural e das práticas produtivas: a introdução da agricultura familiar e seu potencial como modelo social, econômico e produtivo para a sociedade brasileira; a crescente influência e ação do Estado no meio rural, que se deu tanto por meio das políticas para a agricultura familiar como por ações relacionadas à reforma agrária, à segurança alimentar, entre outras; as mudanças no âmbito político e ideológico, em que, por um lado, setores das elites agrárias contrários às mudanças, particularmente no apoio às políticas sociais e de caráter compensatório, viram-se forçados a mudar de posição enquanto, por outro lado, foi sendo construída uma argumentação que visava descortinar as diferenças fundamentais existentes no universo de produtores da agricultura brasileira; e, por último, foram as discussões sobre o desenvolvimento rural relacionado ao tema da sustentabilidade ambiental (SCHNEIDER, 2010), ampliando-se as discussões atuais para a sustentabilidade agrícola, que envolve outras dimensões, tais como a social, a econômica, a política, a institucional, entre outras.

Ressalta-se, nesse contexto, a necessidade de um novo enfoque para a agricultura e o desenvolvimento rural, que construa aspectos de conservação dos recursos naturais, viabilize atividades em pequena escala e modernos métodos ecológicos. Logo, uma atividade produtiva que utilize a base dos recursos locais, que seja sustentável e com um grau de produtividade capaz de gerar produção diversificada, propiciando as condições de reprodução social de famílias e comunidades locais (ARAÚJO \& MAIA, 2012). Como incentivo para essas práticas, verifica-se um direcionamento das políticas públicas para o fortalecimento da agricultura familiar, no sentido de oferecer suporte às práticas agrícolas voltadas para a manutenção das famílias nas áreas rurais.

A atividade agrícola da Cooperativa Hidroçu, localizada em São João do Cariri (PB), objeto do presente estudo, caracteriza-se em termos de estrutura como um sistema produtivo com processos integrados (hidroponia, aquaponia, microalga, dessalinização), sendo a atividade hidropônica a base para a produção agrícola. A hidroponia é uma forma de produção com o cultivo de plantas na água sem utilizar o solo, cujas raízes recebem uma solução nutritiva com os nutrientes essenciais para o desenvolvimento do vegetal (LABHIDRO, 2013) em um ambiente de produção com estufas. Esse método representa uma oportunidade para regiões onde as questões climáticas interferem na produção agrícola tradicional. Desse modo, mesmo tendo como principal insumo a água, é possível explorar as águas subterrâneas para a produção dos produtos hidropônicos e 
manter a produção constante, sem interferência climática. Assim, o sistema de cultivo hidropônico apresenta potencial para contribuir com a sustentabilidade de localidades com baixa precipitação e maior risco de seca, como é o caso da região do semiárido.

Com os processos integrados, tem-se uma atividade com baixo impacto ambiental, cuja proposta é melhorar as condições sociais e econômicas da comunidade. Por tratar-se de uma atividade considerada sustentável em sua produção e com significativa importância para o desenvolvimento local, torna-se imperativa a análise do desempenho e da eficiência desse sistema produtivo, bem como dos problemas sociais, ambientais e econômicos enfrentados.

Essa análise pode ser viabilizada por meio de indicadores de sustentabilidade adequados à atividade agrícola, visando consolidar informações para tomada de decisões e monitoramento das ações desenvolvidas. De acordo com Bolívar (2011), a avaliação da sustentabilidade dos sistemas de produção agrícola, por meio da utilização de metodologias e indicadores, possibilita apontar as tendências de desenvolvimento dos sistemas produtivos.

A partir da preocupação de mensurar a sustentabilidade das atividades agrícolas, diversos sistemas foram desenvolvidos, podendo-se destacar: o Método Indicateurs de Durabilité des Explotations Agricoles (também conhecido como IDEA, BRIQUEL et al., 2001), Bases para estabelecer indicadores (CAMINO \& MULLER, 1993); FIPAT ? Indicador de Segurança Alimentar e Ferramenta de Análise de Políticas (IISD, 2014); KUL - Kriterien Umweltvertraglicher Landbewirtschftung, com critérios de manejo da terra ambientalmente saudável (HEGE; BRENNER, 2004); o ISA - Indicadores de Sustentabilidade em Agroecossistemas (FERREIRA et al., 2012); o IDAS - Índices de Desenvolvimento Agrícola Sustentável (TAVARES, 2004), o MESMIS - Marco para la Evaluación de Sistemas de Manejo de Recursos Naturales incorporando Indicadores de Sustentabilidade (MASERA; ASTIER; LÓPEZ-RIDAURA, 1999), entre outros. O método MESMIS permite avaliar unidades produtivas agrícolas que objetivam tornar-se mais sustentáveis, sendo um método flexível na escolha dos indicadores por permitir a participação dos agentes envolvidos, ou seja, os agricultores. Assim, constitui uma metodologia adequada para avaliar a atividade econômica da Cooperativa Hidroçu, dadas as peculiaridades da gestão cooperada e os processos integrados da Cooperativa, que exige um olhar diferenciado no tocante da análise da sustentabilidade dessa atividade agrícola.

A adoção dessa ferramenta permite mensurar o nível de sustentabilidade da atividade agrícola a partir da identificação das potencialidades e vulnerabilidades da atividade, para incorporar práticas sustentáveis adequadas ao contexto local e a atividade como forma de manter seu funcionamento e, ao mesmo tempo, contribuir para o desenvolvimento local sustentável.

Diante das considerações colocadas, o objetivo do presente artigo é analisar a sustentabilidade de sistemas agrícolas com atividades integradas (hidroponia, dessalinização, microalga e aquaponia), tendo como objeto de estudo as atividades da Cooperativa Hidroçu, utilizando como marco ordenador o Método MESMIS. A relevância deste estudo consiste na utilização de uma metodologia que permite análise da sustentabilidade das atividades agrícolas de uma cooperativa a partir de suas principais características e comportamentos, evidenciados por meio da participação dos próprios atores envolvidos na atividade: os agricultores. Essa participação permite que os indicadores utilizados na análise da sustentabilidade reflitam a realidade do agroecossistema, resultando em uma análise mais coerente da sustentabilidade, cujos resultados servirão para projeção do empreendimento agrícola de forma sustentável para contribuir com a sustentabilidade local.

O presente artigo está estruturado neste início seguido da exposição das bases teóricas que deram sustentação ao estudo, do detalhamento da metodologia utilizada, dos resultados apresentados por dimensão da sustentabilidade e, por fim, das considerações finais e referências do estudo.

\section{Sustentabilidade e indicadores em agroecossistemas}

O termo desenvolvimento sustentável foi reconhecido a partir do Relatório Blundtland ou, como passou a ser conhecido, "Nosso Futuro Comum", da Comissão Mundial sobre Meio Ambiente e Desenvolvimento. O desenvolvimento sustentável surge em uma proposta de harmonização entre o desenvolvimento socioeconômico com 
a conservação do meio ambiente, ênfase na preservação dos ecossistemas naturais e na diversidade genética para a utilização dos recursos naturais. O conceito de desenvolvimento sustentável é apresentado como um processo de transformação no qual a exploração dos recursos, a direção dos investimentos, a orientação do desenvolvimento tecnológico e as mudanças institucionais se harmonizam e reforçam o potencial presente e futuro para atender às necessidades e aspirações humanas (CMMAD, 1991). O conceito foi consolidado na Conferência das Nações Unidas sobre Meio Ambiente e Desenvolvimento - Rio 92 e, de acordo com Barbiere (2007), foi nessa ocasião que foram fixadas as bases para alcançar o desenvolvimento sustentável, formalizando os direitos e as obrigações dos países por meio da Agenda 21.

Em vista desse novo paradigma de desenvolvimento, a sociedade e os setores produtivos ao longo dos anos passaram por diversas transformações que afetaram seus modos de vida, formas de produzir e consumir, desencadeando novas concepções e práticas. Nesse contexto, o desenvolvimento passa a ser um processo de mudança, de transformação estrutural que, necessariamente, envolve as distintas esferas da sociedade e a inclusão de diversas perspectivas: sociais, ambientais, econômicas, políticas, culturais, etc. $O$ desenvolvimento, para ser sustentável, deve incluir tais perspectivas em busca da equidade e da justiça social.

Nas atividades agrícolas, a sustentabilidade constitui um novo paradigma que orienta os sistemas produtivos, de modo que os mesmos possam contribuir com o desenvolvimento social, ambiental e econômico da comunidade. Ferreira et al. (2012) afirmam que é imperativa a mudança na compreensão do papel do espaço rural na conservação e na proteção dos recursos naturais, em que o produtor rural tornou-se protagonista na gestão desses sistemas complexos, diversificados, integrados e interdependentes, na busca por conciliar eficácia econômica, responsabilidade social e proteção do patrimônio natural, tendo como resultado a geração de serviços e produtos para a sociedade.

As controvérsias em torno do tema destacam em diversas correntes básicas: uma vertente que afirma que a sustentabilidade implica fundamental e prioritariamente as questões ambientais ou ecológicas, com foco para conservação dos recursos naturais e redução dos impactos dos agroecossistemas; e outra que afirma que a sustentabilidade deve considerar, além da dimensão ecológica, a socioeconômica ou social (OLMOS \& SANTOS, 2013). Esta última é tomada como uma abordagem mais adequada, considerando o significado do termo desenvolvimento sustentável.

No contexto da agricultura familiar, há um caminho que busca a sustentabilidade por meio de práticas agroecológicas. Fernandes e Pascual (2015) apontam a agroecologia como uma alternativa para a sustentabilidade, uma vez que utiliza o manejo de agroecossitemas a partir da aplicação de princípios ecológicos, incluindo questões socioeconômicas. Nessa mesma linha de pensamento, Camino e Muller (1993) já haviam destacado outros aspectos que merecem destaque: além do manejo adequado dos recursos do agroecossistema, a busca da promoção da equidade e do respeito aos valores da comunidade, $\mathrm{O}$ atendimento às demandas atuais e futuras por melhores condições, bem como a manutenção e a melhora da base dos recursos naturais.

Essas práticas encontram subsídios nas políticas para o desenvolvimento rural sustentável e, assim, maior abrangência em termos práticos nos municípios brasileiros, com abarcamento de diversas atividades agrícolas. Sales e Cândido (2016, p. 25) afirmam que, sem o apoio de políticas e programas estatais, "os agricultores familiares não teriam como melhorar suas condições sociais, econômicas, culturais e até mesmo ambientais". Os autores enfatizam que a agricultura familiar consegue ser muito mais do que uma atividade puramente econômica voltada para obtenção de lucro ou suprimento alimentar das famílias; envolve um número considerável de pessoas e constitui uma atividade econômica, avaliada a partir de parâmetros em diversas dimensões: ambiental, econômica, social e político-institucional, para atingir os princípios da sustentabilidade.

Como suporte, é possível estabelecer um ciclo virtuoso capaz de gerar desenvolvimento e autonomia regional a partir de alguns aspectos: participação efetiva dos atores envolvidos (agricultores e pesquisadores) em todas as fases do processo; interação entre as partes implicadas a partir de ações interdisciplinares, envolvendo pesquisadores de diversas áreas do conhecimento e a experiência dos agricultores; equilíbrio entre as distintas dimensões do desenvolvimento, orientado ao progresso agrícola sustentável; participação do Estado como indutor do processo para construção de novas parcerias; e criação de uma consciência do pensar globalmente e 
do agir localmente, a partir dos esforços voltados às iniciativas do poder público nos seus distintos níveis (municipal, estadual, federal) para a construção do desenvolvimento com base na sustentabilidade (MARTINS, 2000).

A agricultura familiar como uma atividade muito complexa pela sua heterogeneidade, seja em sua forma de organização, viabilidade ou emancipação social dos atores sociais (SALES \& CÂNDIDO, 2016), requer formas de intervenção distintas, a partir da compreensão dos sistemas produtivos em suas características, tipos de práticas produtivas e entendimento em termos de sustentabilidade.

Para atender essas condições, torna-se imprescindível a utilização de instrumentos e medidas que permitam o monitoramento desses agroecossistemas. Sendo assim, os indicadores de sustentabilidade direcionados para o setor agrícola constituem-se em medidas adequadas que fornecem informações importantes para análise e gestão desses sistemas. É importante ressaltar que, de acordo com Ferreira et al. (2012) esses sistemas atuais mais integrados, diversificados e resilientes, implicam em maior complexidade e reforçam a necessidade do monitoramento por meio de métricas e parâmetros, ou seja, indicadores.

Um indicador é uma variável de medida que pode representar uma característica quantitativa ou qualitativa importante para julgamentos das condições do sistema, sejam elas atuais, passadas ou futuras (BOLÍVAR, 2011). Assim, na busca por uma forma de quantificar a sustentabilidade, os indicadores são essenciais para a compreensão da realidade investigada e, por conseguinte, para a orientação do processo de desenvolvimento em bases sustentáveis, conforme destaca Martins (2012). Nesse contexto, é importante destacar o pensamento de Gallopin (1996) sobre indicadores sustentáveis, quando o mesmo afirma a necessidade de identificar as interligações a partir da verificação de vínculos entre as variáveis relacionadas ao desenvolvimento sustentável do contexto investigado, visando ao entendimento do sistema como um todo, em busca de soluções integradas. Nesses termos, os indicadores constituem relevantes parâmetros para caracterizar a realidade investigada, devendo comunicar informações úteis para a elaboração e o planejamento de políticas, a fim de efetivar o processo de desenvolvimento sustentável, em uma perspectiva ampla que contemple a multidisciplinaridade inerente ao contexto (MARTINS, 2013).
Em relação às atividades agrícolas, esses indicadores devem refletir a realidade e as características dos agroecossistemas. Assim, de acordo com Bolívar (2011), a construção de indicadores deve partir das necessidades e dos problemas dos produtores, bem como dos projetos e ações propostas para promoção do desenvolvimento. A partir dessa realidade, elabora-se um marco conceitual que reflita os interesses e as perspectivas dos atores locais, a serem transpostos em variáveis, resultando em indicadores mensuráveis.

Nessa perspectiva, são construídos sistemas para análise da sustentabilidade das atividades agrícolas a partir de um conjunto de indicadores que permita responder as condições atuais da sustentabilidade e orientar as decisões relacionadas ao futuro do agroecossistema, onde os sistemas agrícolas se diferem em termos de composição das variáveis, formas de avaliação, participação dos agricultores ou agentes envolvidos, entre outros. Para Bolívar (2011), a relevância do uso de sistemas de indicadores está na possibilidade de detectar pontos críticos da sustentabilidade, estabelecendo suas causas e possíveis soluções.

É importante ressaltar que a aplicação dos sistemas de indicadores em agroecossistema precisa considerar que os espaços rurais são complexos e podem ser multisetoriais, assim como as pessoas que o habitam podem apresentar características ligadas a pluriatividades (SALES \& CÂNDIDO, 2016). Assim, existem atualmente diversos sistemas para análise da sustentabilidade voltados para as atividades agrícolas, em destaque:

- O Método IDEA visa integrar um conjunto de indicadores na busca por quantificar os vários componentes de um sistema agrícola por meio da atribuição de uma pontuação numérica e ponderação para agregação das informações nas dimensões agro-ecológica, sócio-territorial e econômica. Assim, constitui uma ferramenta de avaliação de sustentabilidade e apoio à decisão, permitindo ao agroecossistema uma reflexão sobre suas próprias práticas. É composto por 37 indicadores que buscam abordar as atividades agrícolas de forma sistêmica. No entanto, cada indicador tem o objetivo de transmitir uma mensagem voltada ao progresso e à durabilidade do agroecossistema (BRIQUEL et al., 2001).

- O Programa Sostenibilidad de la Agricultura y los Recursos Naturales, por meio de um documento 
que estabelece as bases para indicadores, apresenta o marco conceitual da agricultura sustentável, as principais variáveis e estabelece critérios para a definição de indicadores para avaliar situações passadas e futuras no estabelecimento do sistema de monitoramento. Nesse sentido, essa proposta permite medir até que ponto um sistema econômico, social, natural ou integrado é sustentável em longo prazo. Assim, estabelece algumas variáveis para análise da sustentabilidade, tais como: população, necessidade e consumo, recursos, tecnologias, produção, produtividade, capacidade de carga, distribuição e acesso dos recursos de tecnologia, rentabilidade, instituições, variáveis sociais e tempo (CAMINO \& MULLER, 1993).

- Indicadores de Sustentabilidade em Agroecossistemas (ISA) é um sistema integrado para aferição do desem-

\section{MESMIS}

O MESMIS é um sistema criado em 1995 pelo Grupo Interdisciplinar de Tecnologia Rural Apropriada (GIRA) do México. É um método que, de forma cíclica, participativa e multiescalar, busca identificar alterações antrópicas sobre um sistema com base em padrões de sustentabilidade (SOUTO MAIOR et al., 2012). O sistema é uma ferramenta metodológica que possibilita a avaliação da sustentabilidade dos recursos naturais, com ênfase no contexto de produtores agrícolas em nível local; a compreensão das limitações e possibilidades do sistema; a comparação dos sistemas de manejo em termos de sustentabilidade. 0 método representa uma estrutura flexível para se adaptar a diferentes níveis de informação e capacidades técnicas locais, entre outros aspectos. O diferencial da ferramenta é a possibilidade de construção, a partir das experiências e aplicações em diferentes ambientes (MESMIS, 2013).

O MESMIS é orientado por atributos gerais que constituem as bases para a definição do conceito de sustentabilidade, sendo eles: produtividade, estabilidade, confiabilidade e resiliência, adaptabilidade, equidade e autogestão. Nesses termos, a produtividade consiste na capacidade de um agroecossistema gerar um nível desejado de bens e serviços em relação aos seus insumos; a estabilidade descrita como o equilíbrio dinâmico dos ecossistemas ao longo do tempo, mantendo sua harmonia funcional e sua produtividade; a confiabilidade como a capacidade do sistema de manter os benefícios penho econômico, social e ambiental, tendo como objetivo auxiliar na gestão de estabelecimentos rurais. O sistema é composto por um conjunto de 23 indicadores que abrangem os balanços econômico e social, o gerenciamento do estabelecimento, a qualidade do solo e da água, o manejo dos sistemas de produção, a diversificação da paisagem e o estado de conservação da vegetação nativa. Vale mencionar que o ISA já foi aplicado em aproximadamente 500 estabelecimentos rurais, em diferentes regiões do estado de Minas Gerais (FERREIRA et al., 2012).

Além desses sistemas de indicadores, existem atualmente outros sistemas com o propósito de analisar a sustentabilidade das atividades agrícolas. Dentre eles, é possível destacar o MESMIS.

desejados e sua produtividade; a resiliência como a propriedade de um ecossistema retornar às condições de vida originais das populações e espécies depois da ocorrência de impactos graves; a adaptabilidade como a característica de um sistema encontrar o equilíbrio após mudanças ambientais de longo prazo, mantendo seu nível de produtividade; a equidade vista como a faculdade de um sistema distribuir, de forma justa aos beneficiários humanos, os custos e benefícios resultantes, de forma intra e intergerações; e autogestão como a competência do sistema de regular, manter e controlar suas relações com o ambiente externo (MASERA; ASTIER; LÓPEZ-RIDAURA, 1999). Além desses atributos, Olmos e Santos (2013) ressaltam que, em função da flexibilidade, o MESMIS tem como base outros parâmetros:

- a avaliação só é válida para um sistema de manejo em um determinado espaço geográfico, em uma escala espacial;

- requer processo participativo com equipe de participação interdisciplinar;

- não se mede a sustentabilidade por si só, mas por meio da comparação transversal ou longitudinal.

Assim sendo, é uma ferramenta que permite uma análise da sustentabilidade, a partir de atributos e critérios 
de diagnósticos que orientam a avaliação, tomando como base os aspectos limitantes e potencialidades do agroecossistema para estabelecer as variáveis de avaliação da sustentabilidade, mediante a participação dos principais atores envolvidos no processo.

Para operacionalização e aplicação da metodologia, segue-se um conjunto de passos que permite efetivar todo o ciclo de avaliação:

- Fase 1: caracterização do sistema analisado;

- Fase 2: definição dos fatores favoráveis (fortes) e limitações (fracos) da sustentabilidade do sistema;

- Fase 3: seleção dos indicadores e critérios para avaliação;

- Fase 4: medição e monitoramento dos indicadores ao longo do tempo;

- Fase 5: integração e apresentação dos resultados; e
- Fase 6: conclusões e recomendações para melhoria da sustentabilidade do sistema.

Quando esse ciclo se fecha, abre-se nova avaliação (MASERA; ASTIER, M.; LÓPEZ-RIDAURA, 1999, VERONA, 2010).

Nesse sentido, pode-se destacar que essa metodologia permite uma avaliação contínua do sistema investigado, oferecendo subsídios para a incorporação das questões da sustentabilidade na atividade agrícola, de modo que a mesma contribua efetivamente para o desenvolvimento local sustentado. Dessa forma, considerando que o objeto de estudo é a cooperativa agrícola com atividades integradas (hidroponia, aquaponia, microalga e dessalinização) e orientada pela gestão cooperativa, em que as decisões são colegiadas, o método MESMIS, por apresentar uma metodologia flexível que permite a análise da sustentabilidade, a partir da leitura dos próprios agentes envolvidos no agroecoessistema, é um método adequado para a avaliação da sustentabilidade na Cooperativa Hidroçu.

\section{Proposta metodológica para aplicação do MESMIS na cooperativa agrícola Hidroçu}

Para atender ao problema de pesquisa e objetivos propostos, foi realizada por meio de pesquisa bibliográfica uma revisão da literatura pertinente à temática: sustentabilidade e indicadores, método MESMIS, cooperativas, atividade agrícola e hidropônica.

Quanto aos objetivos da pesquisa, o estudo pode ser classificado como pesquisa descritiva devido à necessidade de descrição das atividades, processos produ- tivos e formas de gestão adotadas pela cooperativa; bem como pesquisa exploratória, em virtude do caráter pouco explorado do tema em relação à análise da sustentabilidade em cooperativas com atividades agrícolas integradas por meio do método MESMIS, resultando na geração de novos conhecimentos no contexto das teorias referentes à sustentabilidade e indicadores voltados para sistemas hidropônicos.

\section{Estrutura conceitual e operacional para}

\section{a construção dos indicadores e análise da sustentabilidade}

O método utilizado como marco ordenador para análise da sustentabilidade das atividades agrícolas da Cooperativa Hidroçu foi o MESMIS, a partir das seis fases ou ciclos de avaliação, a saber: caracterização do sistema analisado, definição dos fatores favoráveis e limitações da sustentabilidade do sistema, seleção dos indicadores estratégicos, medição e monitoramento dos indicadores, integração e apresentação dos resultados, seguidas das conclusões e recomendações para melhoria da sustentabilidade do sistema.

O primeiro passo corresponde à caracterização do sistema analisado. O modelo de produção adotado pela
Cooperativa Hidroçu é um sistema de produção integrado com as seguintes atividades: uma unidade de água potável (dessalinização), uma de hortaliças (hidroponia), uma de criação de tilápias (aquaponia) e outra de produção da microalga spirulina.

Na primeira fase, foi utilizada a pesquisa documental para levantar dados e informações disponíveis na cooperativa sobre o projeto implantado e seu funcionamento na comunidade Uruçu em São João do Cariri. Essas informações foram complementadas pela verificação in loco, mediante visitas para reconhecimento do ambiente de estudo e seus aspectos organizacionais e 
funcionais, assim como a averiguação da Cooperativa em seu contexto sociocultural, econômico e ambiental para desenvolvimento local. Para isso, foi realizado um mapeamento das atividades e processos da cooperativa, permitindo uma melhor compreensão de funcionamento, perspectivas e limitações da atividade no contexto interno da cooperativa, como também no contexto externo, em termos de relacionamento com o mercado fornecedor e consumidor e com a comunidade local.

Considerando que o método MESMIS de avaliação de sustentabilidade tem como característica essencial ser um trabalho interdisciplinar, tendo a valorização da participação de todos os atores envolvidos (VERONA, 2010), esse mapeamento utilizou, além da pesquisa documental, entrevistas com cooperados, gestores e agentes envolvidos na implementação do projeto, tornando possível a coleta de informações sobre atividades desenvolvidas (produtos produzidos), processos produtivos (produção hidropônica e suas variações), formas de gestão praticadas pela cooperativa para a condução das atividades de produção, comercialização dos produtos hidropônicos e posicionamento estratégico para manter-se competitiva no mercado, além de aspectos que interferem na atuação da cooperativa. Além disso, buscou-se informações sobre a relação estabelecida pela cooperativa com seu entorno e a contribuição da mesma para o desenvolvimento local.

A utilização do MESMIS, conforme ressalta Verona (2010, p. 56), "é um processo que permite adaptações de acordo com as necessidades específicas dos agroecossitemas que estão sendo avaliados". Dessa forma, o mapeamento realizado na Cooperativa foi fundamental para identificar os pontos fortes e os fracos e, consequentemente, listar um conjunto de indicadores que refletisse a realidade investigada, mediante adaptação do MESMIS para análise da sustentabilidade da atividade hidropônica da Cooperativa Hidroçu.

Assim, o segundo passo correspondeu à definição dos fatores favoráveis e limitações da sustentabilidade do sistema. A partir do mapeamento e da imersão dos pesquisadores junto à cooperativa, foi possível definir os pontos fortes ou fatores favoráveis e as limitações ou pontos fracos da Cooperativa em estudo orientado pelos atributos do método MESMIS (produtividade, resiliência, estabilidade, confiabilidade, adaptabilidade, equidade, autogestão) e seus respectivos critérios de diagnóstico, que serviram de suporte para escolha dos indicadores estratégicos para análise da sustentabilidade da Cooperativa (terceiro passo), conforme Quadro 1.

O quarto passo consiste na medição e monitoramento dos indicadores. Nessa fase foi realizada uma pesquisa de campo. Atualmente, a cooperativa é composta de 22 cooperados que correspondem ao universo da pesquisa; assim foram entrevistados 16 cooperados, correspondendo uma amostra de $73 \%$ do total. A coleta de dados ocorreu mediante a realização de entrevistas com cooperados, orientadas por um formulário estruturado com afirmativas correspondentes aos atributos da sustentabilidade (produtividade, resiliência, estabilidade, confiabilidade, adaptabilidade, equidade, autogestão), permitindo aos próprios cooperados atribuir notas de desempenho com variação entre 0 e 10 , assim como opinar sobre as questões abordadas ou justificar as notas atribuídas.

Logo, foi possível um maior aprofundamento quanto à sustentabilidade da Cooperativa e, por consequência, a seleção do conjunto de indicadores potenciais para análise da cooperativa em seus aspectos sociais, ambientais e econômicos (Quadro 2). Para melhor consolidação das informações levantadas, também foi realizada uma entrevista com a atual gestora, visando estabelecer as perspectivas atuais e futuras da Cooperativa.

O quinto passo do método corresponde à integração dos resultados. Uma característica do método MESMIS destacada por Verona (2010, p. 56) consiste na "exigência da abordagem das dimensões ambientais e socioeconômicas". Assim, o primeiro esforço nesse sentido foi enquadrar os indicadores selecionados para análise da sustentabilidade da cooperativa nas dimensões ambiental, social e econômica, tomando como base a abordagem conceitual de cada dimensão da sustentabilidade e a realidade diagnosticada na Cooperativa. O Quadro 2 mostra as dimensões com seus respectivos indicadores e descrição em função da realidade do Agroecossistema em estudo.

O segundo esforço foi a integração dos dados para a formação do índice de sustentabilidade e apresentação dos resultados. Nesse sentido, as notas para cada indicador foram transformadas em índices com variação 0 - 1 que, agregados, geraram os índices das dimensões econômica, social e ambiental e o ín- 
Quadro 1 - Forças, fraquezas, indicadores e atributos de sustentabilidade.

\begin{tabular}{|c|c|c|}
\hline \multicolumn{3}{|c|}{ Gestão sustentável } \\
\hline Forças & Fraquezas & Indicadores \\
\hline \multicolumn{3}{|c|}{$\begin{array}{l}\text { Atributo e descrição: Produtividade - capacidade da cooperativa de gerar bens e serviços em relação aos seus } \\
\text { insumos. Critério de diagnóstico: retorno e eficiência. }\end{array}$} \\
\hline $\begin{array}{l}\text { - Produtos de qualidade } \\
\text { - Hidroponia }\end{array}$ & $\begin{array}{l}\text { - Baixa produtividade } \\
\text { - Baixo retorno }\end{array}$ & $\begin{array}{l}\text { Preço de venda; produção mensal; qualidade } \\
\text { dos produtos; eficiência do sistema } \\
\text { produtivo; retorno aos cooperados. }\end{array}$ \\
\hline
\end{tabular}

Atributo e descrição: Resiliência - capacidade de recuperar as condições de vida das populações e espécies depois de impactos ambientais. Critério de diagnóstico: conservação e diversidade.

\section{- Sistema integrado das}

atividades produtivas

- Baixo impacto da atividade
Ausência de impactos ambientais; conservação dos recursos naturais; produção hidropônica; diversificação da produção.

Atributo e descrição: Estabilidade - equilíbrio dinâmico da cooperativa ao longo dos anos para funcionar e ter produtividade. Critério de diagnóstico: capacidade de funcionamento.

- Cooperação

- Sistema integrado das atividades produtivas

- Produção contínua (sem sazonalidade)
- Mercado consumidor

- Apoio das instituições

- Redução dos cooperados

- Distância dos fornecedores

- Quantidade de água isponível
Venda dos produtos; participação das instituições; padronização dos processos; quantidade de cooperados; aquisição de insumos; disponibilidade de água para produção.

Atributo e descrição: Confiabilidade - capacidade de manter os benefícios desejados e sua produtividade. Critério de diagnóstico: capacidade para manter a produtividade.
- Produtos de qualidade e
- Instabilidade na produção
sem agrotóxicos
- Canais de distribuição

Escoamento da produção no mercado; satisfação dos consumidores; ampliação da participação da cooperativa no mercado.

Atributo e descrição: Adaptabilidade - capacidade de a cooperativa encontrar o equilíbrio após mudanças ambientais de longo prazo. Critério de diagnóstico: capacidade de mudança e inovação.

\section{- Potencial para diversificar} os produtos
- Apoio do governo e instituições

- Baixa adaptabilidade da spirulina às condições locais
Investimentos; produção da spirulina; grau de adaptação do sistema produtivo às culturas locais; produção de novos produtos.

Atributo e descrição: Equidade - capacidade de distribuir, de forma justa, aos cooperados os custos e benefícios resultantes ao longo das gerações. Critério de diagnóstico: distribuição e participação.

\section{- Baixos rendimentos aos cooperados}

Participação nas atividades; distribuição dos rendimentos.

Atributo e descrição: Autogestão - capacidade de gestão da cooperativa.

Critério de diagnóstico: Autossuficiência organizacional.

- Gestão cooperada

- Baixa participação das instituições e envolvimento da comunidade - Ausência de planejamento formal
Estruturação da cooperativa; planejamento das atividades; envolvimento da comunidade; eficiência na gestão; conhecimento do processo produtivo; capacitação dos funcionários. 
Quadro 2 - Dimensões e indicadores da sustentabilidade da Cooperativa Hidroçu.

\begin{tabular}{|c|c|c|}
\hline Dimensões & Indicadores & Descrição \\
\hline \multirow{10}{*}{ Econômica } & Qualidade dos produtos & Reconhecimento da qualidade dos produtos \\
\hline & Preço de venda & Adequação do preço de venda dos produtos \\
\hline & Quantidade mensal produzida & $\begin{array}{l}\text { Adequação da quantidade produzida por mês para } \\
\text { atender ao mercado }\end{array}$ \\
\hline & Eficiência do sistema produtivo & $\begin{array}{l}\text { Capacidade do sistema produtivo de produzir com qualidade } \\
\text { e em quantidade suficiente para sustentar a cooperativa }\end{array}$ \\
\hline & Venda dos produtos & $\begin{array}{l}\text { Eficiência na venda e escoamento de toda a produção } \\
\text { para o mercado }\end{array}$ \\
\hline & Aquisição de insumos & $\begin{array}{l}\text { Adequação das fontes de fornecimento de materiais } \\
\text { para a produção }\end{array}$ \\
\hline & Satisfação dos consumidores & $\begin{array}{l}\text { Satisfação dos consumidores com os produtos } \\
\text { da cooperativa }\end{array}$ \\
\hline & Produção da spirulina & Reestabelecimento da produção da spirulina \\
\hline & Retorno aos cooperados & Retorno financeiro aos cooperados \\
\hline & Eficiência na gestão & Eficiência na gestão da cooperativa \\
\hline \multirow{7}{*}{ Social } & Quantidade de cooperados & $\begin{array}{l}\text { Adequação da quantidade de cooperados para realizar } \\
\text { os serviços da cooperativa }\end{array}$ \\
\hline & Participação das instituições de apoio & $\begin{array}{l}\text { Existência de instituições de apoio atuando junto } \\
\text { à cooperativa }\end{array}$ \\
\hline & Investimentos de instituições/governo & $\begin{array}{l}\text { Existência de investimentos para ampliação e } \\
\text { diversidade da produção }\end{array}$ \\
\hline & $\begin{array}{c}\text { Grau de adaptação do sistema produtivo } \\
\text { às culturais locais }\end{array}$ & $\begin{array}{l}\text { Possibilidade do sistema produtivo para reproduzir as } \\
\text { culturais locais }\end{array}$ \\
\hline & Participação nas atividades & Distribuição das atividades da cooperativa \\
\hline & Distribuição dos rendimentos & Distribuição da remuneração dos cooperados \\
\hline & Envolvimento da comunidade & $\begin{array}{l}\text { Envolvimento da comunidade com as atividades } \\
\qquad \text { da cooperativa }\end{array}$ \\
\hline \multirow{5}{*}{ Ambiental } & Disponibilidade de água para produção & $\begin{array}{l}\text { Existência de água suficiente para manter a diversidade } \\
\text { de produção }\end{array}$ \\
\hline & $\begin{array}{l}\text { Ausência de impactos ambientais } \\
\text { da atividade }\end{array}$ & $\begin{array}{l}\text { Ausência de impactos ambientais no entorno } \\
\text { provocados pela atividade da cooperativa }\end{array}$ \\
\hline & Conservação dos recursos naturais & Conservação dos recursos naturais (solo e água) \\
\hline & Produção hidropônica & Grau de importância da produção hidropônica \\
\hline & Diversificação da produção & Produção de variedades de produtos \\
\hline
\end{tabular}


dice de sustentabilidade da Cooperativa em estudo, a partir da Equação 1:

$$
I=\frac{X-X \min }{X \max -X \min }
$$

Onde:

$I=$ índice

$X=$ média do indicador

$X \min =$ nota mínima atribuída

$X \max =$ nota máxima atribuída

Os critérios de valoração e análise dos índices seguiram os seguintes parâmetros: $0,00-0,29$, baixa contribuição para a sustentabilidade; $0,30-0,69$, média contribuição; 0,70-1,00, alta contribuição para sustentabilidade. Tomando como base o limiar estabelecido por Ferreira et al. (2012) para avaliar a sustentabilidade de agroecossistemas, em que se considera o índice 0,7 como o

\section{Caracterização das atividades da Cooperativa}

Em 2007, a cidade de São João do Cariri foi beneficiada com o projeto Água - Fonte de Alimento e Renda: uma alternativa sustentável para o Semiárido. O projeto, proposto e coordenado pela Fundação Centro de Referências em Tecnologias Inovadoras (CERTI), com sede em Florianópolis (SC), foi financiado pelo Programa Petrobras Ambiental, com a participação de diversos parceiros técnicos: a Universidade Federal de Campina Grande (UFCG), por meio do Laboratório de Dessalinização (LABDES), realizando a perfuração dos poços e capacitação de pessoal para operacionalização do sistema; a Universidade Federal de Santa Catarina, com o LabHidro e o BioTec, laboratórios responsáveis por desenvolver as atividades pertinentes à hidroponia e pesquisas referentes ao cultivo da spirulina. Posteriormente, outras instituições passaram a fazer parte do projeto, a exemplo dos Governos Municipal, Estadual e Federal, Parque Tecnológico etc.

O projeto inicial tinha como principal objetivo implantar tecnologia social inovadora, que permitisse estimular o empreendedorismo para a geração de emprego e renda e a melhoria da qualidade de vida de comunidades desfavorecidas. De forma mais específica, objetivava a conservação dos recursos hídricos a partir do aproveitamento do rejeito de dessalinização pela prática de limiar da sustentabilidade (ou seja, abaixo desse índice, a situação é considerada indesejável para a sustentabilidade), adota-se aqui que os índices acima de 0,70 representam a situação almejada ou ideal para a sustentabilidade do agroecossistema, denominado aqui marco para a sustentabilidade - limite aceitável. A representação dos índices foi possível por meio de biogramas ou gráficos de radar, como forma de facilitar o entendimento e a interpretação dos resultados.

Para análise dos resultados, utilizou-se o processo de triangulação dos dados primários e secundários, recorrendo-se ao embasamento conceitual que deu suporte ao estudo e às percepções dos pesquisadores.

O sexto passo do método corresponde às conclusões e recomendações para melhoria da sustentabilidade do sistema. Na sequência serão apresentados os resultados das análises, conclusões e recomendações para a sustentabilidade da Cooperativa Hidroçu, a partir do conjunto de indicadores selecionados.

ações sociais, ambientais e econômicas que proporcionassem o desenvolvimento de um modelo sustentável e replicável para outras regiões do Semiárido.

Assim, a proposta baseou-se no aproveitamento do "concentrado de sais" gerado no processo de dessalinização. Convencionalmente, a água salobra retirada de poços tubulares da região, após a dessalinização, gera água potável e um concentrado, que, se devolvido ao solo, causa grandes impactos ambientais. A solução inovadora foi implantar em Uruçu quatro unidades de produção que funcionassem de forma integrada, fazendo uso criativo desse concentrado: uma unidade de água potável; uma de hortaliças, por meio da hidroponia; uma de criação de tilápias (piscicultura); e outra de produção da microalga spirulina. Depois, foi ainda iniciado o cultivo de pimenta de variadas espécies, também no sistema hidropônico (FRANÇA, 2007). Esse sistema permite menor impacto ambiental mediante o aproveitamento de todos os rejeitos do processo de dessalinização. Esse projeto beneficiava os agricultores familiares da Comunidade de Uruçu, no município de São João do Cariri.

Com o término do financiamento, ao final de dois anos, surgiu a necessidade de formalização de um modelo ju- 
rídico para comercialização desses produtos. O modelo mais adequado à realidade local e às características do negócio foi o Cooperativismo. Dessa forma, em 2009, foi criada a Cooperativa Agropecuária de Uruçu (Hidroçu), responsável por dar continuidade ao desenvolvimento sustentado das unidades construídas, em benefício de seus cooperados. Inicialmente, a Cooperativa atingiu o número de 45 cooperados, mas conta atualmente com 22. A sede da Hidroçu está localizada no Sítio Uruçu, em São João do Cariri, que fica a 216 km de distância da capital, João Pessoa.

$\mathrm{Na}$ integração das atividades, a primeira etapa é o processo de dessalinização da água que vem do poço tubular e que, posteriormente, é distribuída para as demais atividades. $O$ processo de dessalinização utilizado na Cooperativa é por osmose inversa que, atualmente, é uma das técnicas mais utilizadas em processos de dessalinização, pois a água do poço não entra em contato com o meio exterior. A estrutura do poço deve ser mantida vedada, contra a entrada de répteis ou outros animais, suas peças deverão passar sempre por manutenção e a qualidade da água deverá ser analisada a cada seis meses (FRANÇA, 2007).

Esse processo de dessalinização resulta em dois tipos de água: permeada (água potável) e concentrada (água com maior concentração de sais). A água potável é distribuída à comunidade por meio de um chafariz localizado nas imediações da Cooperativa e o concentrado é distribuído para as unidades produtivas de acordo com a necessidade de cada uma. Essa integração nas atividades é uma forma de reduzir os custos dos produtos produzidos e amenizar o impacto ao meio ambiente caso essa água concentrada viesse a ter contato com o solo, além de gerar atividade, renda e melhoria na qualidade de vida para as famílias da comunidade de Uruçu.

Outra atividade integrada é a aquaponia que, de acordo com Reis (2007), é o cultivo de peixes integrado à produção de vegetais por hidroponia, principalmente verduras e legumes, cujo objetivo é dar um destino ecologicamente correto ao concentrado salino. Na cooperativa, o sistema é composto por quatro viveiros escavados com capacidade individual de armazenamento de 100 mil litros de água; um sistema de filtragem de água por meio de tanques para decantação, com capacidade para armazenar 7 mil litros cada um; quatro tanques para secagem, cujo objetivo consiste em receber o lodo advindo dos tanques de decantação; casa de bombas contendo dois filtros de piscina equipados com moto bomba trifásica e cinco moto-bombas para oxigenação e movimentação de água entre os viveiros e filtros; sistema de filtros biológicos composto por seis caixas d'água com capacidade de armazenamento de 2,5 mil litros cada e duas caixas d'água com capacidade de armazenamento de 5 mil litros; calhetões para cultivo de pimenta hidropônica compostos por dez calhetões de fibrocimento e duas caixas d'água com capacidade de armazenamento de 3 mil litros cada, utilizadas para preparar a solução nutritiva das plantas e uma moto bomba para gerenciar o sistema.

Outra atividade integrada é a hidroponia, prática agrícola realizada sem a presença do solo. A hidroponia consiste no cultivo de plantas sem solo, em que as raízes recebem uma solução nutritiva balanceada que contém água e todos os nutrientes essenciais ao desenvolvimento da planta (LABHIDRO, 2013). Oliveira (2007) esclarece que a água do solo é substituída por uma solução líqui$\mathrm{da}$, contendo os nutrientes essenciais à planta, tendo como principal vantagem a economia da água e dos nutrientes, resultando em plantas saudáveis cultivadas em local limpo, sem contaminação e sem agrotóxicos.

Juntamente com a água, as raízes das plantas absorvem nitrogênio, fósforo, potássio, cálcio, magnésio, enxofre, ferro, manganês, zinco, cobre, molibdênio e boro. Esses nutrientes são responsáveis pela saúde e crescimento das plantas. Para cada cultura existe uma solução nutritiva diferente. A Cooperativa conta com três estufas para cultivo das hortaliças: uma para a fase inicial e intermediária e duas para as plantas que estão em sua fase final. As estufas têm capacidade produtiva de 16 mil pés de alface por mês, estando atualmente abaixo dessa capacidade, pois parte desta estrutura necessita de manutenção e reparos.

Para a produção da pimenta, a Cooperativa conta com duas formas de plantio: hidropônico e o sistema por gotejamento. Segundo informações do Laboratório de Hidroponia, LabHidro (2013), pelo sistema por gotejamento, as plantas são irrigadas gota a gota por canos chamados de gotejadores, que ficam acoplados junto ao pé da planta.

Pelo sistema de gotejamento, a planta precisa de substrato para que retenha o máximo possível de água e nutrientes, sendo utilizada na Cooperativa a fibra de coco. Mesmo assim, devido à exposição ao sol, a água evapora com maior facilidade, deixando a planta seca rapidamente. Além disso, apresenta a desvantagem de não permitir o reuso da água e da solução nutriti- 
va no sistema produtivo, como acontece na produção da alface. Com o objetivo de agregação de valor dos produtos já existentes, o Ministério da Integração fez a doação para a construção de uma fábrica própria para o processamento da pimenta e de um caminhão para facilitar o transporte das mercadorias.

Para completar o processo integrado, tem-se também a produção da microalga denominada spirulina. Como é uma microalga oriunda de outras condições climáticas, seu cultivo constitui um dos maiores desafios para a Cooperativa, pois é uma atividade que ainda necessita de muitos estudos e experiências, afora presença de um técnico para dar suporte à produção. Isso fez com que a plantação não se consolidasse mas, mesmo assim, a cooperativa mantém a estrutura física inicial destinada à spirulina.

Assim, a estrutura da Cooperativa foi organizada para funcionar de forma integrada utilizando uma pequena área física. No entanto, dispõe de uma área de 3 ha, o que favorece a possibilidade de ampliação e crescimento das atividades. Com esse processo, apresenta estrutura para produzir água potável, alface, rúcula, agrião, almeirão, pimenta e alguns derivados, tilápia e spirulina.

A água é o primeiro produto desenvolvido. É extraída de um poço e, após dessalinização, torna-se apropriada para o consumo. Desse procedimento, para cada 100 litros de água "bruta", 40\% torna-se apropriada para o consumo humano e $60 \%$ torna-se ainda mais salgada, sendo utilizada nas unidades de produção. A quantidade de água consumida mensalmente na produção é de, em média, 50 mil litros.

Atualmente, a alface é o principal produto da cooperativa, pois é responsável pelo retorno financeiro aos cooperados e paga os custos de manutenção da cooperativa. A produção mensal é um torno de 4.200 pés, cuja comercialização ocorre nas feiras das cidades circunvizinhas. Apesar de ser um produto de alta qualidade e com ausência de agrotóxicos, a comercialização em feiras livres e a concorrência direta com outros produtos de baixa qualidade e preço inferior gera uma desvalorização do alimento no mercado.

A pimenta fabricada é comercializada in natura, tendo uma produção média de 200 kg por mês, também beneficiada na fábrica de processamento própria, gerando outras mercadorias, tais como molho de pimenta e pimenta em garrafa. Esses produtos têm mais valor agregado e melhores perspectivas de penetração no mercado.

A tilápia é obtida em dois ciclos anuais. Com essa descontinuidade, ou seja, periodicidade de apenas duas pescas anuais, o acesso ao mercado torna-se restrito pela impossibilidade de estabelecer e fidelizar compradores. Isso gera uma dependência da Cooperativa com algumas instituições, como é o caso da relação estabelecida com a CONAB (Companhia Nacional de Abastecimento), que atende ao Programa Fome Zero do Governo Federal, em que acaba comprando toda a produção não absorvida pelo mercado.

A microalga spirulina, com significativo valor no mercado, atualmente não é produzida pela Cooperativa em função do alto grau de complexidade para produzi-la, o que requer um acompanhamento técnico especializado do qual a cooperativa não dispõe no momento. Esse foi um grande entrave nos propósitos da Cooperativa, pois havia significativas possibilidades de retorno por ser um produto ainda pouco produzido no Brasil.

Mesmo assim, a Hidroçu continuou com suas atividades voltadas para a produção dos demais produtos, mantendo seu funcionamento e sempre buscando novas maneiras de se fortalecer por meio da colaboração das famílias agricultoras envolvidas nesse empreendimento. Atualmente, passa por algumas dificuldades que podem comprometer seu futuro. É nesse ponto que reside a significativa contribuição do presente estudo, em que a análise da sustentabilidade pode mostrar caminhos ou perspectivas para essa atividade, dada sua importância para a comunidade local.

\section{RESULTADOS E DISCUSSÃO: ANÁLISE DA SUSTENTABILIDADE DO AGROECOSSISTEMA}

A sustentabilidade da atividade da Cooperativa Hidroçu foi avaliada a partir das dimensões econômica, social e ambiental, tomando como base a percepção dos cooperados e a análise dos pesquisadores mediante observação do fenômeno estudado (Hidroçu) à luz dos atributos do MESMIS. 
A dimensão econômica foi avaliada a partir dos indicadores: preço de venda, quantidade mensal produzida, eficiência do sistema produtivo, venda dos produtos, aquisição de insumos, satisfação dos consumidores, produção da spirulina, retorno aos cooperados e eficiência na gestão, conforme Figura 1.

De acordo com os resultados, os indicadores melhores avaliados nessa dimensão e que evidenciaram alta contribuição para sustentabilidade, por estarem acima do marco ou limite aceitável para a sustentabilidade do agroecossistema, são: satisfação dos consumidores com os produtos da cooperativa $(0,91)$, eficiência do sistema produtivo $(0,88)$, eficiência na gestão $(0,83)$, qualidade dos produtos $(0,81)$ e aquisição de insumos $(0,79)$. Esses resultados foram evidenciados tanto na pesquisa quantitativa, mediante percepção dos cooperados com a atribuição de notas de desempenho, quanto na percepção dos pesquisadores ao realizar o diagnóstico ou o mapeamento das atividades da cooperativa.

Tais resultados ficaram claros uma vez constatado que a estrutura física da cooperativa foi inicialmente organizada para funcionar de forma integrada, de modo que os resíduos do processo de dessalinização fossem utilizados na produção hidropônica e na aquaponia, com total aproveitamento da água e nutrientes utilizados no processo. Verifica-se que a estrutura do sistema produtivo se mantém integrada e realizando todos os seus processos com o mínimo de impacto da atividade em seu entorno.
As atividades realizadas no processo hidropônico seguem uma padronização que deve ser realizada por todos os cooperados, em que todos realizam as mesmas tarefas em um sistema de rodízio de atividades. Assim, todos conhecem o funcionamento da estrutura e o desenvolvimento das atividades produtivas, visando à eficiência do sistema como um todo. Vale ressaltar que os cooperados entendem a funcionalidade do sistema e sua importância para a qualidade dos produtos produzidos e baixo impacto negativo na comunidade e meio ambiente. Com isso, um ponto favorável da atividade é a produção de produtos de qualidade, ou seja, sem a utilização de agrotóxicos por meio do processo de hidroponia. Isso evidencia que os produtos da Cooperativa têm qualidade para competir no mercado e satisfazer seus consumidores, apresentando grande potencial para ampliação da participação da Cooperativa no mercado.

Em relação à eficiência na gestão, um ponto importante a ser destacado é a adequação da gestão cooperada para a atividade em questão. No entanto, é necessário ressaltar que a falta de qualificação dos cooperados na área de gestão de negócios, o que prejudica o gerenciamento da cooperativa para que ela possa atuar de forma mais competitiva no mercado, ainda é um fator que merece ser melhorado. Nesse sentido, verificou-se certa ineficiência na gestão em termos mercadológicos para projeção dos produtos da cooperativa no mercado, aproveitando suas vantagens competitivas, tan-

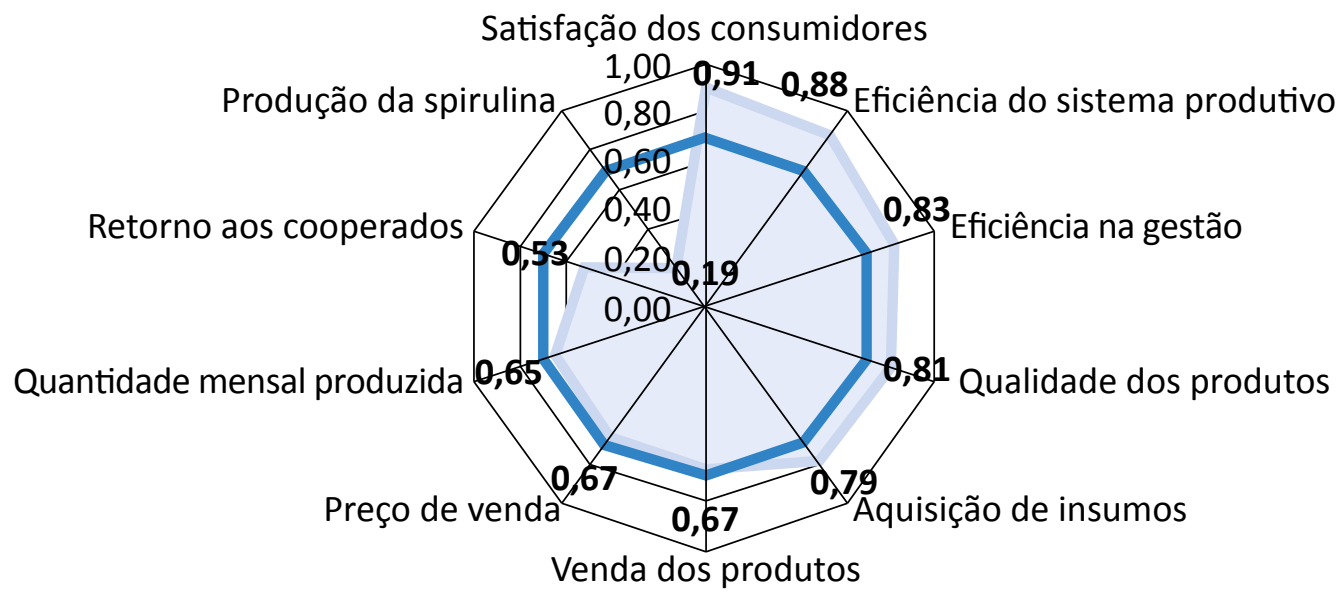

Sustentabilidade do agroecossistema Marco para sustentabilidade - limite aceitávetl

Figura 1 - Indicadores da dimensão econômica. 
to no processo de venda das mercadorias, quanto na compra e aquisição dos insumos.

Quanto à aquisição de insumos, verifica-se que a atividade hidropônica requer materiais (semente, espuma fenólica e nutrientes - ferro, cálcio, potássio, magnésio) não comercializados localmente. Assim, devido à distância dos fornecedores (São Paulo), o preço de compra desses insumos são elevados, sendo repassados para os custos de produção. Mesmo assim, os cooperados ressaltam que a qualidade dos materiais comprados viabiliza a qualidade dos produtos da cooperativa; logo, independentemente da distância, são fundamentais para manter a eficiência do sistema e qualidade dos produtos. Portanto, as formas de aquisição dos insumos na percepção dos cooperados apresenta alta contribuição para a sustentabilidade.

Quanto às relações com o mercado consumidor, constatou-se que os produtos da cooperativa não são posicionados adequadamente no mercado, ou seja, deveriam ser destinados às classes $\mathrm{A}$ e $\mathrm{B}$, devendo ser comercializados em pontos estratégicos, tais como supermercados ou pontos de comércio identificados com marca própria, ou que possuam selos que certifiquem a qualidade dos produtos. No entanto, são comercializados em feiras livres, nas quais os concorrentes são produtos com qualidade e preço inferiores. Além disso, na definição do preço de venda, não há um método adequado de precificação, sendo o valor determinado pelo comportamento e aceitação no mercado. Dessa forma, os índices de venda dos produtos $(0,67)$, preço do produto $(0,67)$ e quantidade mensal produzida $(0,65)$ e retorno aos cooperados $(0,53)$ apresentam média contribuição para a sustentabilidade.

A pesquisa mostrou que, devido a problemas na comercialização dos produtos da cooperativa, tem-se produzido em menor quantidade, o que gera baixo retorno financeiro aos cooperados - fato que tem provocado o desligamento das famílias junto à atividade. Os cooperados afirmam que a quantidade produzida atualmente está muito abaixo da capacidade produtiva da cooperativa, onde apenas é produzida uma quantidade mínima de produtos absorvida pelo mercado. Ou seja, a produção ocorre em função das demandas de mercado, especificamente ao comportamento das feiras livres onde os produtos são comercializados.

Quanto ao indicador produção da spirulina $(0,19)$ apresentando baixa contribuição para a sustentabilidade da cooperativa, constata-se que o produto não se adaptou às condições climáticas locais, necessitando de ajustes e melhoramentos no processo, que requer acompanhamento especializado de que a cooperativa não dispõe atualmente. Esse aspecto também tem provocado redução na produção e baixos rendimentos aos cooperados, dado que a spirulina tem significativo valor de mercado.

Diante do exposto, verifica-se que, mesmo com produtos de qualidade e que proporcionam a satisfação dos consumidores, as formas de comercialização têm provocado a desvalorização dos produtos da Cooperativa no mercado, o que, por sua vez, tem gerado uma instabilidade na produção, ocasionando problemas que interferem na sustentabilidade da cooperativa.

Uma forma de comercialização mais adequada para os produtos da Hidroçu era a venda nas feiras ecológicas. Outras experiências têm mostrado a importância dessas feiras para o fortalecimento das atividades agrícolas, conforme enfatizam Araújo e Maia (2012) em estudo realizado na cidade de Mossoró, cuja feira representou avanços significativos para os agricultores com o aumento da produção e para os consumidores, devido ao acesso a produtos de qualidade.

A dimensão social foi avaliada a partir dos indicadores: quantidade de cooperados, participação das instituições de apoio, investimentos de instituições ou governamentais, grau de adaptação do sistema produtivo às culturais locais, participação nas atividades, distribuição dos rendimentos e envolvimento da comunidade, conforme a Figura 2.

As análises referentes à dimensão social evidenciaram que os índices com alta contribuição para a sustentabilidade, portanto, os melhores avaliados e que estão acima do marco ou limite para a sustentabilidade nessa dimensão, foram: participação das instituições de apoio $(0,79)$, grau de adaptação do sistema produtivo às cultural locais $(0,78)$, distribuição dos rendimentos $(0,76)$ e participação nas atividades $(0,71)$.

Dada a importância da cooperativa para a comunidade Uruçu, afora a da atividade da cooperativa para o desenvolvimento da comunidade local, o apoio de instituições tem sido fundamental para manter o funcionamento da cooperativa desde sua concepção até o momento atual. Portanto, toda a estrutura física e organizacional da Hidroçu foi instalada median- 
te a atuação de instituições, como: Fundação CERTI, UFCG, UFSC, Parque Tecnológico, Governo Municipal, Estadual e Municipal, entre outras. Nesses termos, a cooperativa existe em função das parcerias com essas instituições e da percepção dos cooperados no sentido de avaliar a participação das instituições com alta contribuição para a sustentabilidade, estando relacionada a contribuição histórica dada por essas instituições à cooperativa, e não a participação atual das mesmas. Isso porque, atualmente, a cooperativa conta apenas com o apoio da Prefeitura Municipal, mediante o pagamento da energia consumida, e o PEASA, com o fornecimento dos alevinos para a produção das tilápias.

Um dos aspectos favoráveis que permitem o funcionamento do agroecossistema é o grau de adaptação do sistema produtivo às cultural locais $(0,78)$. Esse índice representa alta contribuição para a sustentabilidade da atividade, uma vez que o sistema produtivo foi estruturado para a produção de vários tipos de produtos, tais como: hortaliças (diversas), pimenta, tilápia, água potável e a microalga spirulina, ampliando a possibilidade de adequar as culturas locais à produção com base na técnica de hidroponia. Dessa forma, verifica-se que a estrutura do sistema produtivo integrado permite diversificar a produção com a utilização de uma pequena propriedade agrícola, oferecendo o mínimo de impacto ambiental da atividade em seu entorno.
Quanto à distribuição dos rendimentos aos cooperados $(0,76)$, terceiro índice melhor avaliado com alta contribuição para a sustentabilidade, verificou-se que, apesar do baixo retorno financeiro, há uma distribuição equitativa dos rendimentos em função da disponibilidade e da contribuição de trabalho de cada membro da cooperativa. Por conseguinte, a cooperativa adota a remuneração por produção, o que, segundo os cooperados, é uma medida justa, pois quem trabalha mais deve ganhar mais, e quem trabalhar menos, consequentemente, deverá ganhar menos. Assim, há uma distribuição adequada das atividades por meio do planejamento semanal, havendo uma participação justa dos cooperados $(0,71)$, em que todos são escalados e têm suas atividades definidas, sendo esse, portanto, um índice que representa alta contribuição para a sustentabilidade.

Vale ressaltar que, mesmo com a participação adequada dos cooperados nas atividades, houve, ao longo dos anos, a redução da quantidade de cooperados. Assim, a quantidade atual de cooperados representa uma ameaça para as atividades da cooperativa. Consequentemente, o índice referente à quantidade de cooperados $(0,68)$ apresentou média contribuição para a sustentabilidade, já que a quantidade de colaboradores está diminuindo com o passar dos anos.

Os resultados mostram que, no início do projeto, houve adesão significativa da comunidade, em que foram

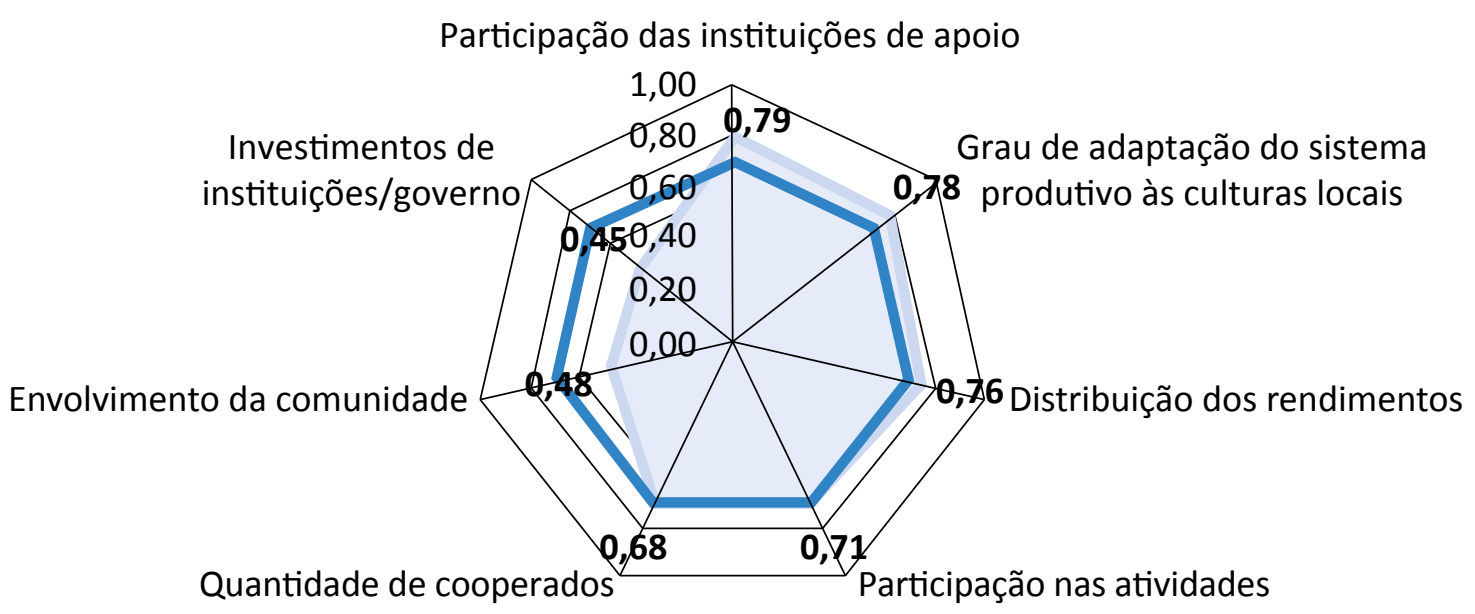

Sustentabilidade do agroecossistema Marco para sustentabilidade - limite aceitávetl

Figura 2 - Indicadores da dimensão social. 
cadastradas 80 famílias. Porém, pouco mais da metade aderiu à proposta e participou, efetivamente, das atividades. Assim, a cooperativa foi formada inicialmente com 45 cooperados, tendo ao longo dos últimos anos reduzido esse número e contando atualmente com apenas 22 colaboradores. Portanto, parte da comunidade local passou a desacreditar do potencial da cooperativa de proporcionar melhoria de condição de vida e de desenvolvimento local, comprometendo o envolvimento de algumas famílias da comunidade nas atividades da cooperativa - aspecto que a gestão atual da Hidroçu busca resgatar. Mesmo assim, o índice referente ao envolvimento da comunidade foi avaliado com média contribuição para a sustentabilidade $(0,48)$, estando abaixo do limite aceitável ou marco para a sustentabilidade do Agroecossistema, cujo resultado foi constatado pelas percepções dos pesquisadores junto à comunidade.

Considerando que a estrutura da Cooperativa necessita de manutenção, foi avaliado o indicador referente à existência de investimento para ampliação e diversidade da produção, sendo esse índice de investimentos de instituições ou governamentais $(0,45)$ o pior avaliado na dimensão social. Esses investimentos, de acordo com os gestores da Cooperativa, dependem do lançamento de editais de órgãos de fomento, não havendo, no momento, nenhum que atenda os interesses da Hidroçu. Para complementar as análises da susten- tabilidade, serão analisados os aspectos ambientais do agroecossistema.

A dimensão ambiental foi avaliada a partir dos indicadores: disponibilidade de água para produção, ausência de impactos ambientais da atividade, conservação dos recursos naturais, produção hidropônica e diversificação da produção, conforme Figura 3.

O índice ambiental melhor avaliado foi importância da produção hidropônica $(0,93)$, seguido da ausência de impactos ambientais da atividade $(0,89)$, conservação dos recursos naturais (solo e água $-0,88$ ) e diversificação da produção $(0,73)$, todos avaliados com alta contribuição, estando todos acima do marco ou limite aceitável para a sustentabilidade do agroecossistema. Verificou-se que os cooperados reconhecem a importância da atividade hidropônica, tendo a preocupação de manter o sistema produtivo e as formas de produzir conforme as exigências desse tipo de cultivo. Esse empenho dos cooperados é um ponto que se mostrou favorável para o funcionamento da atividade e, mesmo diante dos problemas enfrentados, os cooperados alimentam a perspectiva de crescimento e melhor participação da cooperativa no mercado.

Uma preocupação dos cooperados é a redução dos impactos ao meio ambiente, tendo o cuidado de evitar que o concentrado do processo de dessalinização atinja o solo e venha a causar danos. Assim, reconhecem

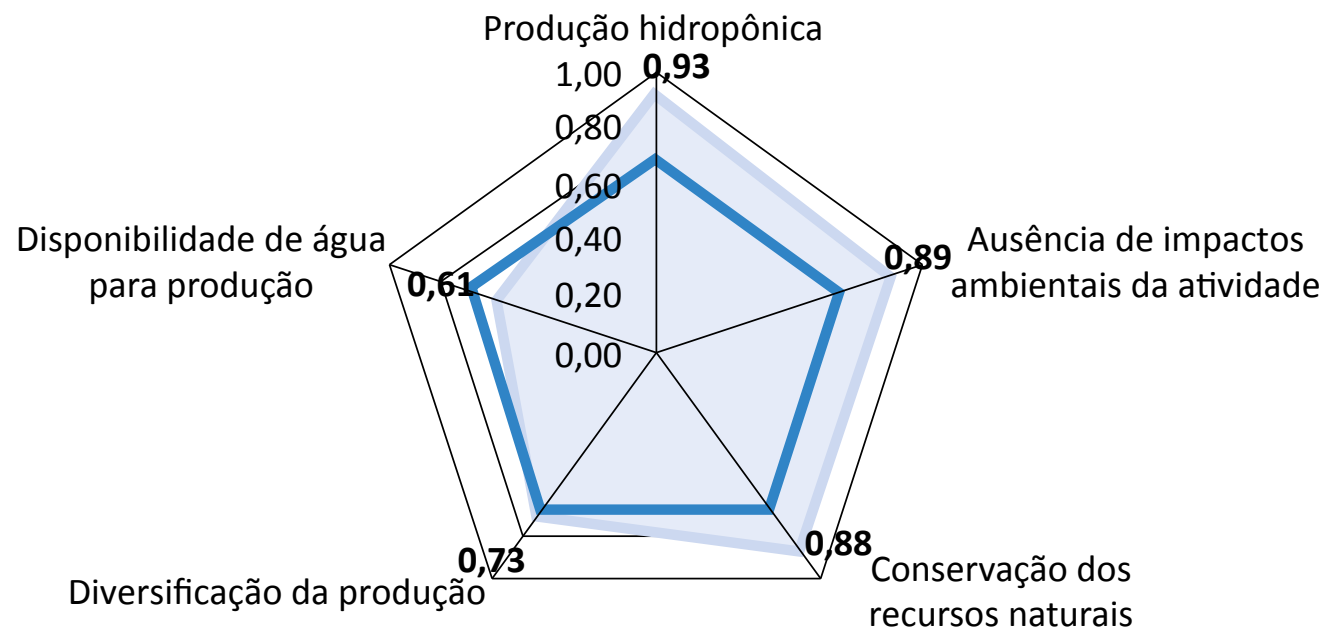

Sustentabilidade do agroecossistema Marco para sustentabilidade - limite aceitávetl

Figura 3 - Indicadores da dimensão ambiental. 
que os recursos naturais - ou seja, a água e o solo precisam ser preservados, e garantem que as atividades da Cooperativa não impactam negativamente esses recursos.

Quanto à diversificação dos produtos, constatou-se que o sistema foi projetado para a produção de diferentes mercadorias. No entanto, atualmente, mesmo reconhecendo essa possibilidade do sistema, o agroecossistema não tem diversificado sua produção em função da baixa vazão do poço ocasionada pelo período longo de estiagem. Considerando que essa é uma situação momentânea, o índice referente à diversificação de produtos foi avaliado com alta contribuição para a sustentabilidade, já que se espera o restabelecimento da produção em pouco tempo - com o aumento das chuvas na região.

Nesse sentido, o índice que apresentou média contribuição para a sustentabilidade foi o de disponibilidade de água para a produção $(0,61)$. Mesmo com um sistema projetado para utilização da água do poço artesiano, cuja produção não depende exclusivamente dos períodos chuvosos, atualmente, dado o longo período de estiagem na região, a atividade da cooperativa está ameaçada. Esse problema já reduziu o potencial de produção e a capacidade de diversificação do cultivo que, atualmente, em termos de hortaliças, só produz alface.

Ante ao exposto, pode-se afirmar que o sistema produtivo foi projetado com atividades de forma integrada para minimizar os impactos ambientais; e os índices ambientais corroboram para esses resultados, tendo em vista que apenas o indicador que trata da disponibilidade de água apresenta média contribuição para sustentabilidade da atividade, tendo os demais apresentado alta contribuição para a sustentabilidade. Esses resultados reforçam os propósitos da atividade no sentido de promover o desenvolvimento local da região mediante a exploração de uma atividade econômica que representa baixo impacto negativo para a comunidade local e seu entorno, ao mesmo tempo em que gera renda por meio da valorização da atividade agrícola sustentável. Os resultados integrados das dimensões econômica, social e ambiental encontram-se expostos na Figura 4.

O melhor índice mensurado foi o ambiental, com 0,81, representando alta contribuição para a sustentabilidade, pois está acima do marco ou limite aceitável para a sustentabilidade do agroecossistema, seguido do índice social, de 0,66 e do econômico, de 0,59, ambos representando média contribuição para a sustentabilidade do agroecossistema, abaixo do limite de sustentabilidade aceitável. Os resultados integrados geraram um índice geral de sustentabilidade de 0,69, analisado como de média contribuição para sustentabilidade da Cooperativa Hidroçu; portanto, abaixo do marco da sustentabilidade do Agroecossistema.

Diante do exposto, verifica-se que a sustentabilidade da cooperativa tem contribuição mais expressiva dos aspectos ambientais que viabilizam um sistema menos vulnerável aos impactos negativos, cujos aspectos sociais permitem, por meio da participação das instituições

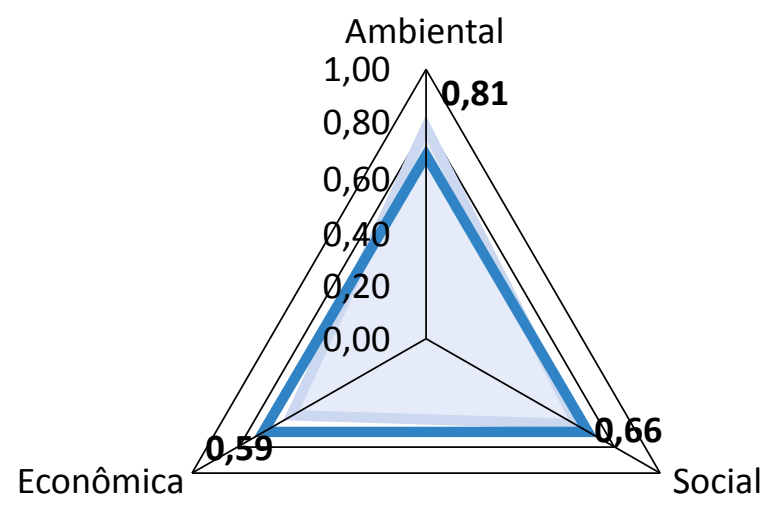

Sustentabilidade do agroecossistema $\square$ Marco para sustentabilidade - limite aceitávetl

Figura 4 - Dimensões da sustentabilidade. 
(CERTI, UFCG, Governos Municipal, Estadual e Federal, Fundação Parque Tecnológico da Paraíba, entre outras), fortalecer a atividade junto à comunidade, de modo que a sustentabilidade econômica possa ser melhorada para permitir a ampliação da renda das famílias, por meio das atividades agrícolas realizadas na cooperativa.

\section{CONSIDERAÇÕES FINAIS}

A sustentabilidade das atividades econômicas e, especialmente das atividades agrícolas, é uma temática com ampla discussão em diversas áreas do conhecimento, esferas pública e privada, tanto em termos conceituais quanto em políticos e metodológicos, como forma de dotar as atividades agrícolas das condições adequadas para atingir níveis considerados sustentáveis. Nesse sentido, a atividade hidropônica constitui uma forma de atividade agrícola que tem como proposta a produção de alimentos sem a utilização do solo, buscando assim reduzir os impactos das atividades produtivas. Ao mesmo tempo, tem a proposta de produzir com um nível de qualidade que atenda as exigências nutricionais e de forma isenta de agrotóxicos.

A Cooperativa Hidroçu, em São João do Cariri (PB), foi projetada com um sistema produtivo para uma produção integrada (dessalinização, produção hidropônica, aquaponia e microalga spirulina) com o mínimo de impactos negativos em seu entorno, visando a ampliar a renda de famílias e fortalecer a agricultura familiar. O sistema integrado das atividades produtivas, mediante a utilização de água subterrânea extraída de poços artesianos, proporciona maior estabilidade às atividades agrícolas por meio da produção contínua, dados os períodos de estiagem na região do Cariri paraibano. Esses aspectos constituem os principais pontos de sustentação e estabilidade da atividade ao longo dos anos de funcionamento.

Dada à complexidade que envolve as questões da sustentabilidade, principalmente em cooperativas agrícolas, torna-se necessário encontrar formas de avaliação da sustentabilidade que permitam melhorar a gestão desses espaços cooperados, tornando-os mais competitivos e com maiores perspectivas de desenvolvimento ao longo dos anos, uma vez que envolvem atividades que geram renda e trabalho para pessoas que não dispõem de outras alternativas de sobrevivência. Dessa forma, o objetivo que orientou o presente estudo foi analisar a sustentabilidade de sistemas agrícolas com atividades integradas (hidroponia, dessalinização e aquaponia), tendo como objeto de estudo as atividades da Cooperativa Hidroçu em São João do Cariri (PB), a partir do método MESMIS. A partir dos estudos realizados à luz dos atributos do MESMIS (produtividade, resiliência, estabilidade, adaptabilidade, confiabilidade, equidade e autogestão) que apontou os pontos fortes e fraquezas do agroecossistema, foi identificado um conjunto de indicadores estratégicos e potenciais para análise da sustentabilidade da Cooperativa, em seus aspectos econômico, social e ambiental, tendo a participação dos cooperados nesse processo de análise.

Os resultados mostraram que as atividades agrícolas desenvolvidas na Cooperativa Hidroçu apresentam contribuições à sustentabilidade, principalmente no que concerne à dimensão ambiental, cujos processos integrados permitem maior controle e padronização das atividades realizadas pelos cooperados, em que eles reconhecem a importância da atividade hidropônica para redução dos impactos da atividade agrícola no solo, valorizam a preservação dos recursos naturais, assim como apostam na Cooperativa como alternativa agrícola promissora em uma região pela qual, evidentemente, a maioria dos cooperados tem um sentimento de apego, especialmente no que se refere à cooperativa, que vai além de uma fonte de renda ou de trabalho, mas um ambiente de conquistas da própria comunidade.

Nesse sentido, foi possível constatar que a Cooperativa é um sistema social que requer a participação de instituições de apoio para dar suporte técnico, capacitação, orientação e direcionar investimentos para a manutenção de seu sistema e atividades produtivas. Uma vez que atua como um sistema cooperativo, requer também o envolvimento da comunidade para atingir seus objetivos enquanto entidade social e agente propulsor do desenvolvimento local. Nesses aspectos, a Cooperativa Hidroçu mostrou-se como um sistema importante para a comunidade. No entanto, em função dos rendimentos não representarem a principal renda das famílias, uma vez que apresentam baixo retorno aos cooperados, houve a redução da quantidade de membros ao longo dos anos. Diante dessa situação, verifica-se a necessidade de melhorar os mecanismos de venda e formas de precificação dos produtos, de modo que se permita um 
posicionamento adequado dos produtos no mercado e vantagem competitiva para a Cooperativa.

Foi possível verificar que os cooperados e a gestão atual da Cooperativa têm mantido todos os esforços para o bom funcionamento da Hidroçu em busca do fortalecimento de suas atividades, na captura de novos investimentos e no envolvimento da comunidade, visando agregar mais famílias para aumentar a produção e, assim, ampliar a participação no mercado.
Em termos de aplicação da metodologia, mesmo com a adequação do Método MESMIS para análise do sistema produtivo estudado, vale ressaltar uma limitação em relação a não ponderação dos indicadores de sustentabilidade utilizados. Essa limitação foi minimizada mediante análise, utilizando a triangulação dos dados e a participação dos cooperados e gestores da cooperativa, o que permitiu gerar um conjunto de informações consistentes e que retratam a realidade da Cooperativa.

\section{REFERÊNCIAS}

ARAÚJO, J. P.; MAIA, Z. M. G. Agroecologia, soberania alimentar e comercialização solidária na Feira Agroecológica de Mossoró-RN: o enlace da sustentabilidade. Raízes, v. 32, n. 2, jul.-dez. 2012.

BARBIERE, J. C. Gestão ambiental empresarial: conceitos, modelos e instrumentos. São Paulo: Saraiva, 2007.

BOLÍVAR, H. Metodologías e indicadores de evaluación de sistemas agrícolas hacia el desarrollo sostenible. Red de Revistas Científicas de América Latina y el Caribe, v. 8, n. 1, p. 1-18, 2011.

BRIQUEL, V.; BOURDAIS, J.; GIRARDIN, P.; MOUCHET, C.; VIAUX, P. La méthode IDEA (indicateurs de durabilité desexploitations. Ingénieries, n. 25, p. 29-39, 2001.

CAMINO, R.; MULLER, S. Sostenibilidad de la agricultura y los recursos naturales: bases para establecer indicadores. San José, C.R.: Instituto Interamericano de Cooperación para la Agricultura/Proyecto IICA/GTZ, 1993. 134p. (Série Documentos de Programas/IICA, n. 38).

CMMAD - COMISSÃO MUNDIAL SOBRE MEIO AMBIENTE E DESENVOLVIMENTO. Nosso Futuro Comum. 2. ed. Rio de Janeiro: Editora da Fundação Getulio Vargas, 1991.

FERNANDES, L. A. O.; PASCUAL, U. Análise da eficiência da agricultura familiar agroecologista. Revista lberoamericana de Economía Ecológica, v. 24, p. 221-233, 2015.

FERREIRA, J. M. L.; VIANA, J. H. M.; COSTA, A. M.; SOUSA, D. V.; FONTES, A. A. Indicadores de Sustentabilidade em Agroecossistemas. Informe Agropecuário, Belo Horizonte, v. 33, n. 271, p. 12-25, nov./dez. 2012.

FRANÇA, K. B. Água: fonte de alimento e renda - uma alternativa sustentável para o semiárido. Campina Grande: UFCG/LABDES, 2007.

GALLOPIN, G. C. Environmental on sustainability indicators and the concept of situational indicators: a system approach. Environmental Modeling and Assessment, v. 1, p. 101-107, 1996.

HEGE, U.; BRENNER, M. Kriterien Umweltverträglicher Landbewirtschaftung (KUL). Bayerische Landesanstaltfür Landwirtschaft (LfL) - Instituitfür Agrarökologie, Ökologischen Landbauund Bodenschutz Vöttinger. Alemanha: FreisingWeihenstephan, 2004.

IISD - INTERNATIONAL INSTITUTE FOR SUSTAINABLE DEVELOPMENT. Food Security Indicator \& Policy Analysis Tool (FITAP) - Guidebook. Canadá: IISD, 2014. 
LABHIDRO - LABORATÓRIO DE HIDROPONIA DA UNIVERSIDADE FEDERAL DE SANTA CATARINA (UFSC). Hidroponia no Brasil. Disponível em: <http://www.labhidro.cca.ufsc.br/hidroponia-no-brasil>. Acesso em: dez. 2013.

MARQUES, F. C.; OLIVEIRA, D. Agricultura ecológica al sur de Brasil: de alternativa a contratendencia. Íconos Revista de Ciencias Sociales, Quito, n. 54, p. 87-106, jan. 2016.

MARTINS, M. F. Gestão Sustentável em Atividade Hidropônica: um estudo na cooperativa Hidroçu - Cooperativa Agropecuária de Uruçu em São João do Cariri-PB. Projeto individual de pesquisa. Unidade Acadêmica de Administração/ Centro de Humanidades/UFCG, Campina Grande, 2013.

. Modelo de monitoramento do nível de sustentabilidade urbana: uma proposta de operacionalização e validação dos seus constructos. Tese (Doutorado)-Programa de Pós-Graduação de Recursos Naturais, Universidade Federal de Campina Grande, Campina Grande, 2012.

MARTINS, S. R. Estratégia para a construção do ideário da sustentabilidade agrícola. Agroecologia e Desenvolvimento Rural Sustentável, v. 1, n. 2, abr./jun. 2000. Disponível em: <http://www.emater.tche.br/docs/agroeco/revista/n2/13artigo3.htm>. Acesso em: abr. 2015.

MASERA, O.; ASTIER, M.; LÓPEZ-RIDAURA, S. Sustentabilidad y manejo de recursos naturales: el marco de evaluación MESMIS. México: Mundi-Prensa, 1999. 109p.

OLIVEIRA, J. L. B. de. Água: fonte de alimento e renda - uma alternativa sustentável para o semiárido. Florianópolis: UFSC/LABHIDRO, 2007.

OLMOS, M. A.; SANTOS, W. G. El valor de la sustentabilidad. Ciencia y Agricultura, v. 10, n. 1, p. 91-100, jan./jun. 2013.

REIS, T. D. S. dos. Água: fonte de alimento e renda - uma alternativa sustentável para o semiárido. Florianópolis: BIOTEC/LABHIDRO, 2007.

SALES, R. M. M.; CÂNDIDO, G. A. Sistema de indicadores para ser aplicado na agricultura familiar: uma análise a partir da organização, da viabilidade e do potencial emancipatório. In: CÂNDIDO, G. A.; LIRA, W. S.(Orgs.). Indicadores de sustentabilidade em agroecossistema: aplicações em diversos tipos de cultivo e práticas agrícolas no Estado da Paraíba. Campina Grande: EDUEPB, 2016.

SCHNEIDER, S. Situando o desenvolvimento rural no Brasil: o contexto e as questões em debate. Revista de Economia Política, v. 30, n. 3 (119), p. 511-531, jul./set. 2010.

SOUTO MAIOR, M. M.; CÂNDIDO, G. A.; NÓBREGA, M. M.; FIGUEIREDO, M. T. M. Estudo comparativo entre métodos de avaliação da sustentabilidade para unidades produtivas agroecológicas. In: ENCONTRO NACIONAL DA ANPPAS, 6., 2012. Anais... Belém-PA, 2012.

TAVARES, E. D. Da agricultura moderna à agroecológica: análise da sustentabilidade de sistemas agrícolas familiares. 230f. Tese (Doutorado em Desenvolvimento Sustentável)-Centro de Desenvolvimento Sustentável (CDS) da Universidade de Brasília, Brasília, 2004.

VERONA, L. A. F. A real sustentabilidade dos modelos de produção da agricultura: indicadores de sustentabilidade na agricultura. Horticultura Brasileira, v. 28, n. 2, jul. 2010. 